\title{
Hard-shell mating in Neohelice granulata: the role of ecdysone in female receptivity and mate attraction
}

\author{
María P. Sal Moyano ${ }^{1}\left(\right.$ ) Tomás Luppi $^{1} \cdot$ Daniel A. Medesani ${ }^{2} \cdot$ Colin L. McLay $^{3}$ • \\ Enrique M. Rodríguez ${ }^{2}$
}

Received: 10 November 2016 / Revised: 17 February 2017 / Accepted: 18 February 2017 / Published online: 1 March 2017

(C) Springer-Verlag Berlin Heidelberg 2017

\begin{abstract}
Most brachyuran females become receptive during the intermolt period, a condition considered "derived". However, as far as we know, studies testing the existence and function of pheromones in decapods are based on species which have mating linked to molting, a condition considered as "ancestral". For the first time, we studied some physiological and morphological processes involved in Neohelice granulata intermolt female crabs becoming receptive and potentially attracting males. We found that receptive females have mobile vulvae opercula due to a softening process of the cuticle hinge which showed lower calcium levels compared to the hinge of unreceptive females. Local softening of the hinge was stimulated by a low concentration of ecdysone during the intermolt period. A putative pheromone liberated by receptive females to attract males is presumed to be released through the mobile vulvae and not through the urine.
\end{abstract}

Keywords Ecdysteroids · Hard-shell mating · Cuticle softening $\cdot$ Vulvae $\cdot$ Pheromones

María P. Sal Moyano

salmoyan@mdp.edu.ar

1 Instituto de Investigaciones Marinas y Costeras (IIMyC), Consejo Nacional de Investigaciones Científicas y Técnicas (CONICET), Universidad Nacional de Mar del Plata (UNMdP), Funes 3350, 7600 Mar del Plata, Argentina

2 Department of Biodiversity and Experimental Biology, FCEN University of Buenos Aires, Institute of Biodiversity, Experimental and Applied Biology (IBBEA), CONICET-UBA. Ciudad Universitaria, Pab. II, C1428EGA Buenos Aires, Argentina

3 School of Biological Sciences, University of Canterbury, PB 4800, Christchurch, New Zealand

\section{Introduction}

Mating in Brachyura may be restricted to the molting period when soft-shell females become receptive, i.e., morphologically able to copulate, which is considered the "ancestral" condition, as observed in the post-molt mating of both portunids and cancrids. However, most brachyuran females become receptive during the intermolt period, as seen in ocypodids and grapsoids, a condition considered "derived": a sample of 100 brachyuran species drawn from 30 families shows 70 which are hard-shell while only 30 are soft-shell maters (McLay and López Greco 2011, see their Tables 2,3). The receptive period in females that copulate during the intermolt period depends on the vulvae form. The vulva of crabs is defined as the aperture located in the sternum of the third pereonite, used for both intromission and egg-laying (Guinot et al. 2013 for eubrachyuran crabs). The vulva or gonopore of grapsoid crabs is covered by an operculum (a hood-like projection of the sternum), which is attached to the sternum through a hinge or membrane (Hartnoll 1968; McLay and Sal Moyano 2016). In receptive females, the operculum becomes temporarily mobile during the intermolt period, allowing the male gonopod to be inserted during copulation (McLay and López Greco 2011; McLay and Becker 2015; McLay and Sal Moyano 2016). Both the operculum and hinge normally present lower calcium levels compared to the adjacent exoskeleton of the sternum, as reported for six species of grapsoid females (McLay and Sal Moyano 2016). It has been proposed that the female operculum becomes mobile due to a "decalcification" process (Hartnoll 1968; Henmi and Murai 1999). However, although the hinge shows the lowest values of calcium, no differences were found in its calcium levels during the reproductive cycle of the varunid crab Hemigrapsus sexdentatus (McLay and Sal Moyano 2016). 
It has been well demonstrated that growth of crabs during molting is a process positively regulated by ecdysteroid hormones, with ecdysone playing a major role in "decalcification" of the carapace (for a review, see Chang 1995). The main ecdysteroid hormone secreted by the $Y$ organ of crustaceans is $\alpha$-ecdysone, which is peripherally converted to $\beta$-ecdysone (20-hydroxyecdysone), identified as the active hormone involved in molting. However, no previous studies have been conducted to see whether ecdysone is involved in signaling vulvae mobility caused by softening of the hinge in receptive intermolt females.

Receptive grapsoid females, besides having mobile vulvae opercula, attract males for mating through the liberation of pheromones (McLay and López Greco 2011). This physiological process leads to sex recognition, and mating. Pheromones are recognized as chemical signals released and received by individuals of the same species to promote a specific reaction (Wyatt 2011). It has been widely demonstrated in the animal kingdom that hormones can act as pheromones (Chang 2011). Although more than 1800 different types of pheromones have been identified, few of them were characterized in marine organisms (Wyatt 2009). In decapod crustaceans, many studies have recognized the existence of sexual pheromones (e.g., Gleeson 1991; Asai et al. 2000; Hardege et al. 2002; Kamio et al. 2002; Atema and Steinbach 2007; Kamio and Derby 2011), although evidence about their chemical identity is wanting (Chang 2011).

In crustaceans, the sensitivity to chemical stimuli depends on both the reproductive and molting stages (Hardege and Terschak 2011). Concerning the reproductive stage, chemical signals have been recognized as relevant cues for mating interactions (Dunham 1988; Bushmann and Atema 2000). In aquatic species, the courtship involves the liberation of pheromones by receptive females, which encourage reproductive behaviors in males, such as the pre-copulatory behavior (e.g., Eales 1974; Gleeson et al. 1984; Dunham 1988; Kamio et al. 2002; Christy and Rittschof 2011). In those decapods, whose mating is associated with molting, sexual pheromones are frequently released either just before or after the molting process, to stimulate the courtship or copulation (e.g., Karplus et al. 2000; Chang and Kaufman 2005). The possibility that sexual pheromones could be represented in these species by the ecdysteroids secreted by the $\mathrm{Y}$ organ has been suggested by early studies (Horn et al. 1966; Kittredge et al. 1971), although others did not find any effect of ecdysteroids in courtship or mating behavior (Atema and Gagosian 1973). Moreover, in the lobster Homarus americanus, a gland associated with the urine bladder might be a source of pheromones released in the urine (Bushmann and Atema 1996). In this species, the full picture of pheromones involved in reproduction and other social interactions has been reported by Atema and Steimbach (2007).

Crustaceans in which molting and reproduction have been de-linked, the ovary itself could be able to synthesize ecdysteroids, as suggested by Subramoniam (2000). In addition to the chemical signals excreted in the urine, ovarian signals (indicating readiness to spawn) could also attract males for mating, particularly in those species with hard-shell (McLay and López Greco 2011). Therefore, a direct liberation of pheromones from the ovary to the seminal receptacle and mobile vulvae of receptive females could be a testable hypothesis.

The semi-terrestrial burrowing crab Neohelice granulata (Dana 1851) is considered a keystone species of South American salt marshes, mud flats, and estuaries, its distribution ranging from Northern Patagonia, Argentina $\left(42^{\circ} 25^{\prime} \mathrm{S}, 6^{\circ} 36^{\prime} \mathrm{W}\right)$ to Rio de Janeiro, Brazil $\left(22^{\circ} 57^{\prime} \mathrm{S}\right.$, $42^{\circ} 50^{\prime} \mathrm{W}$ ) (Spivak 2010). The mating system of N. granulata is based on the defense of burrows constructed by males and used as a copulatory chamber (Sal Moyano et al. 2012a). Neohelice granulata females become sexual mature at a carapace width $>19 \mathrm{~mm}$ (López Greco and Rodríguez 1998). During the reproductive season (spring and summer months), mature females are in the intermolt period when they become receptive. Receptive females are recognized when their vulvae opercula becomes mobile and can be displaced by the male gonopods during copulation. Females can become receptive up to six times in a single breeding season (Sal Moyano et al. 2012b). While receptive, males are attracted to females, presumably by some chemical signal (Sal Moyano et al. 2012b). During the non-breeding season (autumn months), females usually molt. When molting, females have a soft skeleton and, therefore, a mobile vulvae operculum. However, males are not attracted to soft females, and therefore, no mating occurs at molting in this species (Sal Moyano et al. 2012b).

In this context, and taking as model a crab species with a derived condition of mating (i.e., not linked to molting), we have tested the following hypotheses: (1) the vulvae mobility of receptive females depends on a softening process of its cuticle hinge involving changes in calcium levels; (2) ecdysone is signaling such a softening process during the intermolt period, advertising female receptivity; and (3) the pathway of pheromone release involves the mobile vulvae of receptive females.

\section{Materials and methods}

\section{Calcium levels in the vulvae of receptive females}

Crabs were captured in Mar Chiquita Coastal Lagoon (MCL, $37^{\circ} 45^{\prime} \mathrm{S} ; 57^{\circ} 19^{\prime} \mathrm{W}$ ), an oligo-polyhaline estuary 
located in Buenos Aires Province, Argentina. Only mature crabs (CW >19 mm, López Greco and Rodríguez 1998) were captured. Carapace width $(\mathrm{CW})$ was taken as the reference size variable and measured with calipers at a precision of $\pm 0.01 \mathrm{~mm}$. Unreceptive females (CW ranging from 25 to $33 \mathrm{~mm}, N=20$ ) were collected during the non-reproductive season (May to July). During the breeding season (September-February), females (CW ranging from 25 to $32 \mathrm{~mm}, N=20$ ) were collected and transported to the laboratory. The receptive period of females was monitored daily in the laboratory by pushing the operculum to check for mobility: the pleon was lifted, and the opercula were gently probed using fine forceps, under a binocular stereoscope. When the opercula became mobile, it could be pushed inwards like a trapdoor, indicating that females were receptive (Brockerhoff and McLay 2005a; Sal Moyano et al. 2012b). The duration of female receptivity is defined as the time elapsed from the first day; a female has mobile opercula up to the day and it becomes immobile again (Sal Moyano et al. 2012b). Unreceptive females were always characterized by non-mobile operculae.

Once in the laboratory, crabs were placed in natural seawater aquaria $(30 \times 35 \times 25 \mathrm{~cm}, 26 \mathrm{~L}$ capacity, filled with $3 \mathrm{~L}$ ), at a density of four crabs/aquarium, under a controlled photoperiod of $12: 12 \mathrm{~h}$, salinity of $23 \mathrm{~g} / \mathrm{L}$, and continuous aeration. Ambient room temperature was $24.5 \pm 1.5^{\circ} \mathrm{C}$. Crabs were fed daily with rabbit pellet food (15\% protein content), and water was changed weekly. Crabs were maintained for a maximum of 1 month in the laboratory and then replaced by fresh animals. No mortality was observed.

Both kinds of females (receptive and unreceptive) were sacrificed in the laboratory by placing them in a freezer at $-20^{\circ} \mathrm{C}$ for approximately $30 \mathrm{~min}$. The area surrounding the vulva was dissected, dried at room temperature $\left(23-25^{\circ} \mathrm{C}\right)$, and coated with gold-palladium, to be further inspected under a Jeol JSM-6460LV scanning electron microscope provided with EDAX Genesis XM4-Sys 60, and equipped with a multichannel analyzer EDAX mod EDAM IV, sapphire $\mathrm{Si}(\mathrm{Li})$ detector. Quantitative data were analyzed by means of the EDAX Genesis 5.11 software. The level of calcium was measured as its percentage mass in relation to other elements of the tissue sample (carbon and oxygen) using an energy dispersive spectroscopy X-ray analysis (EDXA). Following the descriptions from Hartnoll (1968), Sal Moyano et al. (2012b) and McLay and Sal Moyano (2016), three areas of the vulvae were differentiated to examine calcium levels: the operculum, the hinge (both forming the vulva), and the adjacent exoskeleton $(N=20$ for both receptive and unreceptive females).

A two-way ANOVA (Zar 1999) was used to evaluate differences in the calcium levels among the three vulvae areas (opercula, hinge, and adjacent exoskeleton), and between both female types (receptive and unreceptive). The Tukey test (Zar 1999) was used for multiple comparisons among the levels of both considered factors.

\section{In vivo injection and in vitro incubation experiments with $20-\mathrm{OH}$-ecdysone to stimulate female receptivity}

\section{In vivo injection experiments}

To test whether the ecdysteroid 20-hydroxyecdysone (20-OH-ecdysone) stimulates female receptivity during the intermolt period, $N$. granulata females were captured at MCL in the pre-reproductive season (August) when gonads become fully developed, and therefore, females were able to become receptive in captivity (Ituarte et al. 2006). Only mature, non-ovigerous, and intermolt (according to Rodríguez Moreno et al. 2003) females were captured. Once in the laboratory, all animals were acclimated for $48 \mathrm{~h}$ to the following environmental conditions: photoperiod 10:14 (L:D), temperature $18 \pm 1^{\circ} \mathrm{C}$, and salinity of $23 \mathrm{~g} / \mathrm{L}$. Females weighing $10 \pm 1 \mathrm{~g}(20<\mathrm{CW}<25 \mathrm{~mm})$ were used for the experiments.

20-OH-ecdysone (Sigma Co.) was first dissolved in analytical grade ethanol, and then in crustacean physiological saline (Cooke et al. 1977); final concentration of ethanol in this solution was $10 \mu \mathrm{L} / \mathrm{mL}$. The hormone was added in quantities so as to reach three different concentrations (1, 10 , and $100 \mathrm{ng} / \mathrm{g}$ of body mass) after injecting $50 \mu \mathrm{L}$ of the ethanol-saline solution. The same solution, at the same volume, was injected to controls but with no hormone added.

Twenty females were randomly assigned to each treatment and control. Each female was isolated in a plastic circular container of $1 \mathrm{~L}$ capacity $(12 \mathrm{~cm}$ diameter) filled with $200 \mathrm{~mL}$ of natural seawater. Crabs were fed with rabbit pellet food three times a week. After $40 \mathrm{~min}$ of feeding, water was changed in all containers, females were injected, and their receptivity inspected by testing the mobility of the vulvae opercula. Females were injected at the base of the fourth or fifth pairs of pereiopods, by means of a $1 \mathrm{~mL}$ syringe provided with a $27 \mathrm{G}$ needle, according to Rodríguez et al. (1992) and Zapata et al. (2003). The experiment lasted for 4 weeks. Once a female was found receptive (either with-when females have recently laid eggs and remain with mobile opercula for few hours-or without extruded eggs), it was removed from the experiment and placed in another aquarium together with a mature male of similar size, to test if either guarding or copulation occurred. As a negative control, non-receptive females were also placed with males. Guarding was recognized by the male holding the female with his chelae or caged inside his legs, while effective copula was detected after observing the pair in the "rostrum to rostrum" position (female over the male) with both abdomens opened (as described by Sal Moyano et al. 2012a). According to previous studies, the 
observer was located $1 \mathrm{~m}$ from the experimental aquarium, enough distance to observe the crabs without affecting their behavior (Sal Moyano et al. 2012a). Both male and female were left in the aquarium for $2 \mathrm{~h}$ and monitored every 10 min by the observer.

Females were dissected after freezing them for $30 \mathrm{~min}$ to check the maturity stage of the ovary. An expanded ovary, covering all the hepatopancreas, of dark violet color was considered to be in the ultimate stage of development, ready to extrude oocytes. Since injected ecdysone could stimulate the beginning of the molting process, a sample of the female pleon edge $\left(1 \mathrm{~mm}^{2}\right)$ was cut with dissecting scissors and observed under an optical microscope to verify the molting stage, according to Rodríguez Moreno et al. (2003). A Chi-square test was used to analyze differences among all treatments and control.

\section{In vitro incubation experiments}

In vitro experiments were conducted during July and August. Mature, non-receptive, intermolt females measuring $25-27 \mathrm{~mm} \mathrm{CW}$ and previously acclimated as mentioned above were employed. After freezing each female for $30 \mathrm{~min}$, the area surrounding the vulva was dissected and used for the experiment, assigning the left to the treatment with ecdysone and the right vulva to the control, with no hormone added. These were incubated for $48 \mathrm{~h}$ in $2 \mathrm{~mL}$ well plates filled with M199 culture medium (Sigma Co.). Two treatments with 20-OH-ecdysone levels were used: one at $2.5 \mathrm{ng} / \mathrm{mL}$ and the other at $25 \mathrm{ng} / \mathrm{mL}$, corresponding to the hemolymphatic hormone concentration theoretically expected for $10 \mathrm{~g}$ females injected with 1 and $10 \mathrm{ng} / \mathrm{g}$ of 20-OH-ecdysone, respectively. In all cases, osmolality and $\mathrm{pH}$ of the culture medium were adjusted to the values corresponding to the crustacean physiological saline from Cooke et al. (1977). There were 20 replicates per treatment.

Calcium levels in these vulvae were measured using $\mathrm{X}$-ray EDS, after processing the samples under the same methodology described above. A paired Student $t$ test was used to compare calcium levels in each ecdysone concentration with control.

\section{How are male-attracting pheromones released by females?}

Both adult males (CW ranging from 28 to $32 \mathrm{~mm}$ ) and nonovigerous intermolt adult females (CW ranging from 27 to $32 \mathrm{~mm}$ ) were collected from MCL throughout the breeding season (September to February). In the laboratory, sexes were kept separate and acclimation conditions were the same as those described above. Only receptive females were used. The receptivity of females was confirmed by checking operculum mobility. The experiment consisted of preventing females from releasing the putative male-attracting pheromones by blocking the mobile vulvae and/or the external pore of the urinary glands located at the base of the second pair of antennae. Blocking was performed using cyanoacrylate glue, after completely drying the area to be blocked with absorbent paper. To ensure security, blocking material in excess was used to cover all around the vulvae and the area containing the external pores of secretory urinary glands. The cyanoacrylate glue has been used in other crustaceans to block openings or to glue materials to the carapace in behavioral experiments; thus, it is assumed not to affect behavior (e.g., Berry and Breithaupt 2010; Reinhart et al. 2012).

Twenty females were assigned to each of the following treatments: [T1] females with mobile vulvae blocked, [T2] females with excretory gland pores blocked, and [T3] females with both vulvae and excretory gland pores blocked. The control consisted of receptive females without any blockage. Each female from each treatment was submitted to a $3 \mathrm{~h}$ trial, together with a male, and any guarding or copulation between partners recorded every $10 \mathrm{~min}$ by an observer located $1 \mathrm{~m}$ from the experimental aquarium to avoid affecting crab behavior. The size difference between sexes was never larger than $4 \mathrm{~mm} \mathrm{CW}$. Each trial was run in a glass aquarium of $26 \mathrm{~L}$ capacity $(30 \times 35 \times 25 \mathrm{~cm})$ and filled with $3 \mathrm{~L}$ of natural seawater at $23 \mathrm{~g} / \mathrm{L}$ which was used. A temperature of $23 \pm 2{ }^{\circ} \mathrm{C}$ and a photoperiod of 14:10 (L:D) were maintained throughout.

Statistical differences in the proportion of courtship/copula among treatments and control were analyzed by means of a Chi-squared test.

\section{Results}

\section{Calcium levels in the vulvae of receptive females}

Differences in calcium levels were found in the three vulvae areas between receptive and unreceptive females (two-way ANOVA, $P<0.001)$. The Tukey test showed that receptive females had differences among the three areas $(P<0.001)$, showing the lowest calcium levels in the hinge, medium values in the operculum, and the highest ones in the adjacent skeleton; while in unreceptive females, the adjacent skeleton showed a significant $(P<0.001)$ higher calcium level with respect to both the hinge and the operculum, while no differences $(P>0.05)$ were noted between these latter two (Fig. 1). Comparisons of each area, showed, only in the case of the hinge, a significant $(P<0.001)$ lower calcium level in the receptive females compared to the unreceptive ones (Fig. 1). Vulvae of unreceptive and receptive females are shown in Fig. 2: the former presented a smooth hinge (Fig. 2a), while the latter a wrinkled hinge (Fig. 2d). 
Fig. 1 Mean calcium level ( \pm standard error) of exoskeleton adjacent to vulva, hinge, and operculum, for both receptive $(N=14)$ and unreceptive $(N=20)$ females. Asterisk indicates significant differences between both kinds of females (Tukey test after a two-way ANOVA, $P<0.001)$. Different letters indicate significant differences among the three areas, for each kind of female (Tukey test after a two-way ANOVA, $P<0.001)$

Fig. 2 Vulvae of Neohelice granulata females: Operculum (o), hinge (h), and adjacent skeleton (as). a Unreceptive female $(N=20)$ : the hinge (the white line shows its length) is smooth (according to Sal Moyano et al. 2012b). b Receptive female: the hinge (the white line shows its length) carries cuticle secretions (arrow) over it $(N=6)$. The white square shows the exact area, where the calcium level was measured. c Detailed view of the cuticle secretions (arrows) covering all the hinge area. $\mathbf{d}$ Receptive female $(N=14)$ : the hinge (the white line shows its length) is wrinkled as a result of stretching during gonopod insertion followed by closing of the opercula (according to Sal Moyano et al. 2012b). The white square shows the exact area, where the calcium level was measured
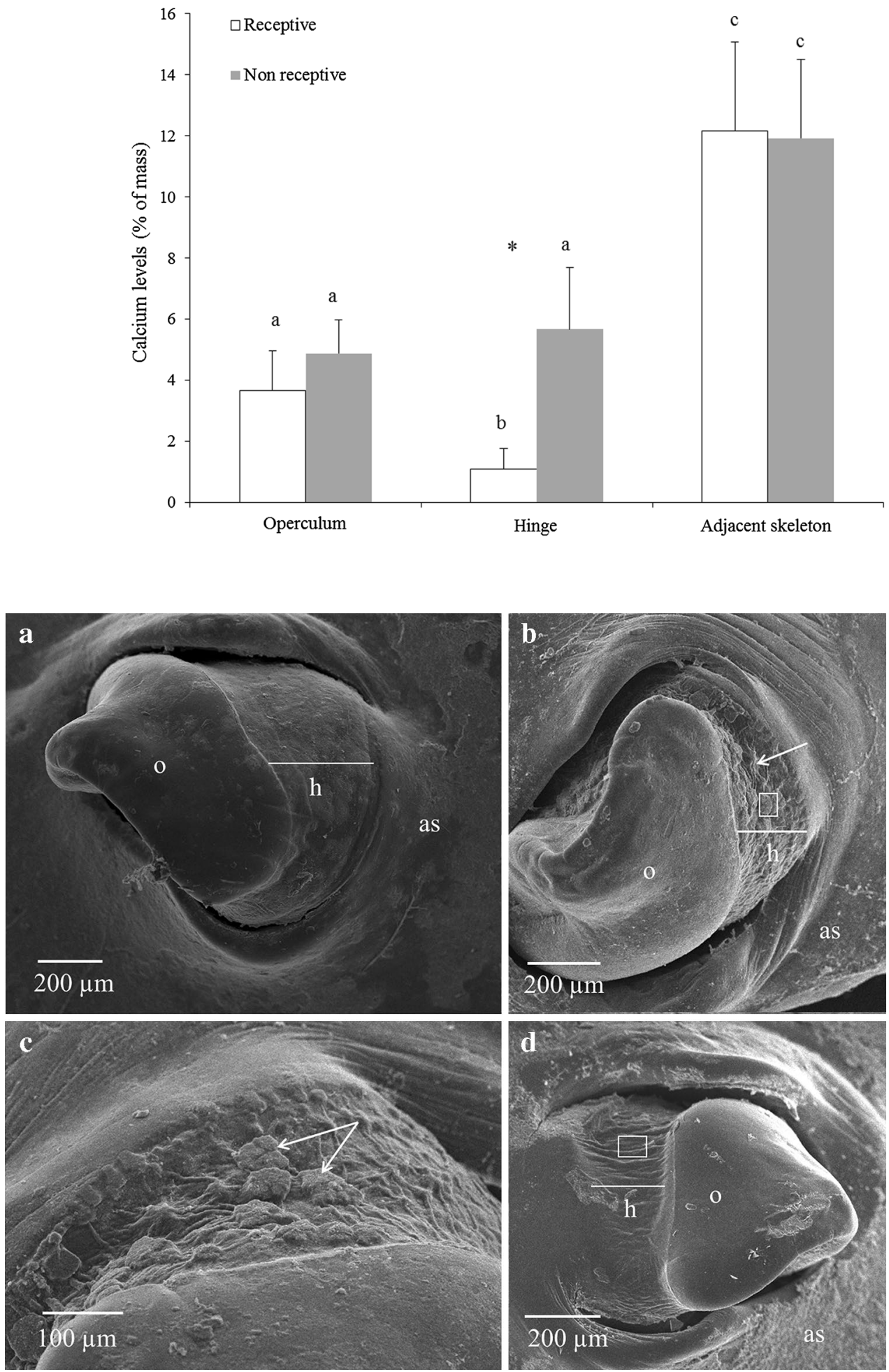

The vulvae of six receptive females presented cuticle secretions in their hinge (Fig. 2b). Secretions looked like a cuticle crystalline material in the form of granules (Fig. 2c). Secretions were abundant and covered all the hinge area (Fig. 2c), and thus, calcium levels were measured on them. The cuticle secretions showed significantly higher calcium levels $(12.6 \pm 6.3 \%$ of mass $)$ - similar to the ones of the adjacent skeleton $(12.1 \pm 2.9 \%$ of mass $)$ - compared to the ones of the hinge of receptive females without secretions $(1.1 \pm 0.7 \%$ of mass $)(t=3.92, P<0.0001)$. Thus, these hinge-calcium level measurements were not considered in the analysis. 


\section{In vivo injection and in vitro incubation experiments with $20-\mathrm{OH}$-ecdysone to stimulate female receptivity}

\section{In vivo injection experiments}

We found that the lowest concentration of the 20-OHecdysone (treatment 1) caused a significantly higher proportion of females to develop mobile operculae than both the control $\left(\chi^{2}=4.27, d f=1, P<0.05\right)$ and the highest concentration of the hormone-treatment $3-\left(\chi^{2}=4.29, d f=1\right.$, $P<0.05$ ) (Fig. 3). On the contrary, no differences were found between treatments 1 and 2, nor between treatment 2 or 3 with respect to control. All females that became receptive copulated with males in the aquaria, while non-receptive females did not. All receptive females had expanded dark violet ovaries at the ultimate stage of development, ready to extrude oocytes. The analysis of the pleon edge showed no differences between the control and treatments, indicating that neither of the hormone concentrations stimulated the molting process.

\section{In vitro incubation experiments}

The same cuticle secretions described in [1] were found on the hinge of females treated with both ecdysone concentrations: 65 and $30 \%$ of females treated with the concentrations of 2.5 and $25 \mathrm{ng} / \mathrm{mL}$, respectively. Thus, for testing differences in calcium levels on the hinge between treated and control females, we considered only the treated females without secretions on their hinges. In any case, cuticle secretions were found on the vulvae hinge of control females. Treated females with the lowest ecdysone concentration $(2.5 \mathrm{ng} / \mathrm{mL})$ which did not

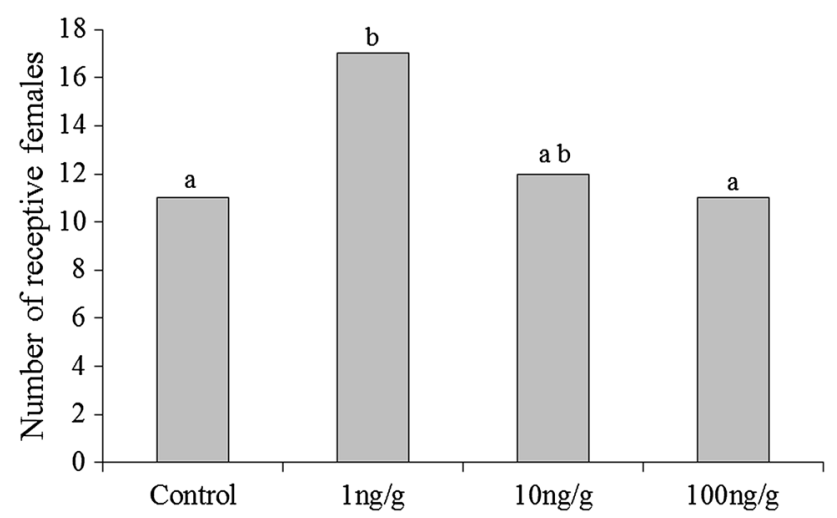

Fig. 3 Results from the in vivo experiment to stimulate female receptivity. Three ecdysone concentrations were injected: [T1] $1 \mathrm{ng} / \mathrm{g}$, [T2] $10 \mathrm{ng} / \mathrm{g}$, and [T3] $100 \mathrm{ng} / \mathrm{g}$. The control consisted of injecting a saline-ethanol solution only. The lowest proportion of females with mobile vulvae was seen in the control (Chi-square test, $P>0.05$ ). Different letters indicate significant differences among the control and the treatments show the presence of secretions on their hinge $(35 \%)$ had significantly $(P<0.01)$ lower calcium levels compared to the hinge of control females. However, despite finding lower calcium levels on the hinge of treated vulvae compared to control ones, no mobility of the opercula was found in any case. For females treated with the $25 \mathrm{ng} /$ $\mathrm{mL}$ ecdysone concentration, no differences $(P>0.05)$ were found in calcium levels between the hinge of treated females which did not show the presence of secretions (70\%) and control ones.

\section{How are male-attracting pheromones released by females?}

Significant differences were encountered among the treatments and the control $\left(\chi^{2}=31.77, d f=3, P<0.001\right)$ : both control receptive females and receptive females with their excretory gland pores blocked (T2) were able to attract males for guarding/copulation, while receptive females with their vulvae blocked, alone (T1 vs control: $\chi^{2}=11.55, d f=1, P<0.001$; T1 vs T2: $\chi^{2}=12.13, d f=1$, $P<0.01)$ or in combination with the urinary gland pores blocked (T3 vs control: $\chi^{2}=19.6, d f=1, P<0.001$; T3 vs T2: $\left.\chi^{2}=16.94, d f=1, P<0.01\right)$, did not attract males for guarding or copulation (Fig. 4).

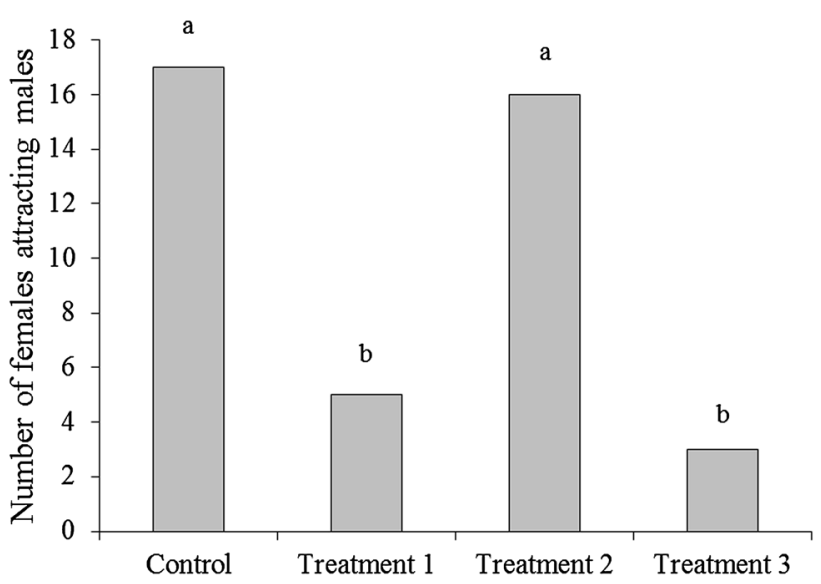

Fig. 4 Results from the experiment of male-attracting pheromones released, in receptive females. [T1]: mobile vulvae blocked, [T2]: excretory gland pores blocked, and [T3]: both vulvae and excretory gland pores blocked. Control: receptive female without any blocking. The lowest proportion of females with guarding or copulation was seen in the control (Chi-square test, $P>0.05$ ). Different letters indicate significant differences among the control and the treatments 


\section{Discussion}

\section{Calcium levels in the vulvae of receptive females}

When grapsoid females are ready to mate their operculae become mobile, and this has been a priori assumed to be due to "decalcification" of the hinge line (Hartnoll 1968, 2006; Henmi and Murai 1999). Accordingly, in the mobile hinge of receptive females, we have found hingecalcium levels lower than those showed by the unreceptive ones, confirming that in $N$. granulata mobilization of the opercula and softening of the hinge effectively occurs, at least in part, because of a "decalcification" process of the hinge. However, in Hemigrapsus sexdentatus, calcium levels of the hinge did not vary during its reproductive cycle; instead, other mechanisms were suggested to be involved in the operculum mobilization, such as polymerization or glycosylation of specific chitin glycoproteins of the cuticle (McLay and Sal Moyano 2016). Some other studies made in decapods show changes in glycoprotein composition of the cuticle during the molting cycle (Shafer et al. 1994), or eventually, different proteins were found in the abdominal arthrodial membrane compared to the skeleton mineralized cuticle (Andersen 1998). Even so, it has also been accepted that changes in cuticle proteins and calcification during the molting cycle are related processes: some cuticle proteins, such as acid or glycol-proteins, are involved in nucleating calcium crystals (Roer et al. 2001; Dillaman et al. 2005, 2013). In the case of $H$. sexdentatus, calcium levels in the hinge were measured during a single breeding cycle (unreceptive females that became receptive), while in $N$. granulata, they were measured in unreceptive females collected in the non-reproductive season and receptive females captured in the breeding season. Thus, it is possible that changes in calcium levels during the breeding season, although being receptive and unreceptive females, are lower and not detectable with the X-ray EDS technique. The molt cycle in all crabs includes softening involving "decalcification" and apolysis, separating the new from the old exoskeleton, followed by hardening involving re-calcification and tanning of chitin and proteins (Roer and Dilliman 1984; Dillaman et al. 2013). However, in hinge softening of hard-shell mating crabs, there is no apolysis, because no new cuticle is created, and there is less need to decalcify the hinge which is already low in calcium (McLay and Sal Moyano 2016). To some extent, likening hinge mobilization to molting is misleading. The origin of hard-shell mating may have involved evolution of a low calcium hinge followed by use of an enzyme to soften the organic matrix of the hinge.

Our finding showing that both the operculum and the hinge have low calcium levels in all analyzed females, compared to the adjacent skeleton, is similar to that reported for other grapsoids (McLay and Sal Moyano 2016). The same authors suggested that the derived condition of mating not linked to molting (as that of some crabs) could have, therefore, evolved from vulvae with lower calcium levels, which could facilitate, during the intermolt period, the local softening of only this area, instead of softening of the whole exoskeleton. Besides, the presence of secretions with high calcium levels found in the mobile hinge of receptive $N$. granulata females suggests that they were formed as a result of the decalcification process. We hypothesized that secretions could be one way of making them flexible, by extracting it from the hinge and depositing it on the exterior by the tegumental glands which lie below the epidermis. Some studies on carapace calcification during molting of decapods, through scanning electron micrographs, showed the presence of small spherulitic granules after calcium accumulation for the mineralization process (Roer and Dillaman 1984; Dillaman et al. 2005, 2013). Those granules look morphologically similar to the secretions found in the current study, suggesting that the process of cuticle hinge decalcification/mineralization is the similar to that observed for molting. It has been largely demonstrated that during the molting process, calcium is high in the hemolymph of premolt individuals, which is attributed to calcium resorption from the old cuticle, decreasing in post-molt individuals because of the subsequent calcium transport from the hemolymph to the new post-molt cuticle (e.g., Robertson 1960; Greenaway 1985). Moreover, calcium uptake from seawater can occur (Greenaway 1983). In the estuarine crab $N$. granulata, the calcium-rich secretions of the small hinges could be used for a further re-mineralization of the hinge, in addition to the calcium uptake from either seawater or internal sources.

\section{In vivo injection and in vitro incubation experiments with 20-OH-ecdysone to stimulate female receptivity}

In the current study, we have shown through the in vivo experiment that a low dose of 20-OH-ecdsyone injected into the hemolymph produced a local decalcification of the hinge -without inducing molting- and mobilization of the opercula. In addition, the in vitro experiment showed that relatively low concentrations of ecdysone stimulated hinge vulvae to decalcify and that the ecdysone acts directly on the vulvae tissue. However, in this latter experiment, we did not find opercula mobility, likely due to the fact that the process of the vulvae becoming mobile might be longer than $48 \mathrm{~h}$.

During intermolt, low basal circulating levels of 20- $\mathrm{OH}$-ecdysone were detected in several crustacean species (Skinner et al. 1985; Chen et al. 2012). During premolt, ecdysone can peak to more than 100-fold greater than intermolt levels, to induce decalcification of the old 
exoskeleton, as well the synthesis of the new cuticle (Skinner et al. 1985). No data about ecdysone circulating levels have been reported during hinge vulvae decalcification, in species that mate during intermolt, such as $N$. granulata. However, taking into account: (1) the administered dose of ecdysone that was effective to produce hinge decalcification (1 ng/g of body mass); (2) the mean mass of females used (10 g); and (3) the relatively large volume of hemolymph in the studied species (near $40 \%$ of body mass, according to Rodríguez and Dezi 1987), we can estimate a circulating level of 20-OH-ecdysone of about $2.5 \mathrm{ng} / \mathrm{mL}$ just after injecting, which represents an increment of about twice the values reported for intermolt, taking as reference the estuarine crab Callinectes sapidus (Chen et al. 2012). Therefore, the possibility that the vulvae hinge decalcification can be triggered at a low ecdysone hemolymphatic level could be quite plausible. The fact that the higher doses of ecdysone used were not effective to induce hinge decalcification could be attributed to one or more additional, complex effects of 20-OH-ecdysone as a molting hormone; the induction of a higher degradation by P-450-dependent hydroxylases (Mykles 2011), caused by moderate levels of circulating ecdysone, could not also be ignored.

On the other hand, the stimulus responsible, under physiological conditions, for the increase of ecdysone secretion needed for the vulvae hinge softening remains elusive; in this sense, a possible hormone secreted by the fully ripe ovaries, acting on the $\mathrm{Y}$ organ, should be considered; in this sense, several peptidic and lipophilic hormones have been described as modulatory of ecdysone secretion at the Y organ (Webster 2015). Another possibility to be seriously considered is the secretion of ecdysone by the ovary itself, which would exert a local effect on the vulvae epidermis, to promote softening. The possibility of the crustacean ovary as a source of ecdysteroids has been previously suggested by Subramoniam (2000). In other arthropods, such as both hemimetabolous and holometabolous insects, the production of ecdysteroids by the ovary has been widely confirmed (Bellés 1998).

\section{How are male-attracting pheromones released by females?}

In those decapods that mate just after molting, the high levels of ecdysone that take place during the premolt period are also stimulating the final maturation of the ovary (Nelson 1991). Besides, the role of ecdysone as a possible sexual pheromone has been already proposed in early studies (Kittredge et al. 1971). In the case of crabs with the derived condition of mating not linked to molting, as we stated above, the origin of hard-shell mating may have evolved to softening of the cuticle hinge. As we demonstrated here, the $20-\mathrm{OH}$-ecdysone is signaling such a process, likely by inducing the expression of the enzymes responsible for cuticle decalcification. However, ecdysone is not a plausible candidate for a sexual pheromone, since males are not attracted to soft females who are hard-shell maters. Alternatively, a more parsimonius hypothesis is to attribute mate attraction to an ovarian hormone.

McLay and López Greco (2011) suggested that an ovarian hormone, released when the gonad was reaching maturity, could signal to males the reproductive status of females and that ova release was imminent. The blocking experiments carried out in the current study demonstrated for the first time that a sex pheromone is certainly involved in the guarding behavior of $N$. granulata. Moreover, since receptive females with their urinary gland pores blocked engaged in guarding/copulatory behavior with males, such pheromone seems to be released by receptive females through their mobile vulvae and not through the urine. In this sense, the hypothesis about the existence of a sex ovarian pheromone is reinforced, because its release would occur directly, from the ovary and then through the seminal receptacle and mobile vulvae. On the contrary, in most decapod species, where molting and mating are closely linked, biological activity of sex pheromones has been found in the urine (Bushmann and Atema 1996). For example, a recent study in Callinectes sapidus identified a component of the urine that was hypothesized to function as a sex pheromone involved in courtship (Kamio et al. 2014). The female urine of the crayfish Pacifastacus leniusculus was selective in favoring reproduction with some males and not others in a gregarious context (Berry and Breithaupt 2010).

Male attraction to females has been previously observed in Neohelice granulata, by either or both distance and contact chemical signals (Sal Moyano et al. 2014a). The putative ovarian pheromone seemed to act as a distant signal, although this requires further confirmation. Observations of male attraction to receptive female Hemigrapsus sexdentatus also indicate a non-contact signal (Brockerhoff and McLay 2005b). The presence of "contact" sexual pheromones, characterized as cuticle exudates, has been frequently described in decapod crustaceans (Borowsky 1991; Kamio et al. 2002; Caskey and Bauer 2005; Ekerholm and Hallberg 2005; Herborg et al. 2006; Bauer 2011). In this respect, the calcium-rich secretions observed on the vulvae hinge of $N$. granulata receptive females could also be part of some kind of contact sex pheromone, different from ecdysone. Interestingly, $N$. granulata males are capable of recognizing females which are close to become receptive, by means of leg contact, accepting them inside their burrows. Although these females are not morphologically receptive, because their vulvae hinge are still immobile, they might be physiologically receptive through emission of 
a chemical signal (Sal Moyano et al. 2014b). However, vulvae of females that were receptive for some days less frequently showed the presence of secretions (experiment 1 ). It could be that secretions may initially be used as contact sex pheromones, while in females close to becoming receptive the cuticle hinge starts to decalcify. Subsequently, receptive females could release a further distance chemical signal. In this way, $N$. granulata females could show a flexible behavior, using contact pheromones when they find a male burrow for copulation just immediately after becoming receptive or distance pheromones, when looking for a male burrow while being already receptive. In the soft-shell mating crab Telmessus cheiragonus, two kinds of pheromones were involved in mating behavior: a "distance pheromone" inducing pre-copulatory behavior and a "contact pheromone" inducing copulation (Kamio et al. 2002). Contact pheromones should be relatively insoluble in water to remain attached to the body surface. In the shrimp Palaemonetes pugio, males respond to an insoluble substance, a cuticular compound on the exoskeleton of post-molt parturial females (Caskey et al. 2009a), specifically a glucosamine or a related compound, serving as a female contact sex signal for mate recognition (Caskey et al. 2009b). In the hermaphroditic shrimp Lysmata boggessi, a cuticular hydrocarbon seems to act as a contact sex pheromone (Zhang et al. 2011). Further studies are necessary to elucidate the chemical compounds of the secretions which may act as both contact and distance sex pheromones in $N$. granulata.

In conclusion, we found that (1) receptive females have mobile vulvae opercula due to a hinge-softening process in which calcium levels were lower compared to the hinge of unreceptive females, (2) 20- $\mathrm{OH}$-ecdysone at low concentrations stimulates intermolt females to soften the vulvae hinge and become receptive, and (3) a putative pheromone released by receptive females to attract males could be liberated through their mobile vulvae and not through their urine.

Acknowledgements We wish to thank to Martin Lorusso for his help in the laboratory experiments. We gratefully acknowledge the three anonymous reviewers for their helpful comments on the manuscript.

\section{Compliance with ethical standards}

Funding Financial support was given by Agencia Nacional de Promoción Científica y Tecnológica: PICTs 1317 and 0763. Grants from both Consejo Nacional de Investigaciones Científicas y Técnicas (PIPI2015, code 11220150100100CO) and the University of Buenos Aires (UBACYT 2016 scientific program, code 20020150100060BA) have also contributed to the current study.

Conflict of interest The authors declare no competing or financial interests.
Ethical approval All applicable international, national, and/or institutional guidelines for the care and use of animals were followed. This article does not contain any studies on human participants performed by any of the authors.

\section{References}

Andersen SO (1998) Characterization of proteins from arthrodial membranes of the lobster, Homarus americanus. Comp Biochem Phys A 121:375-383

Asai N, Fusetani N, Matsunaga S, Sasaki J (2000) Sex pheromones of the hair crab Erimacrus isenbeckii. Part 1: isolation and structures of novel ceramides. Tetrahedron 56:9895-9899

Atema J, Gagosian RB (1973) Behavioral responses of male lobsters to ecdysones. Mar Behav Physiol 2:15-20

Atema J, Steinbach M (2007) Chemical communication and social behavior of the lobster, Homarus americanus, and other decapod Crustacea. In: Duffy J, Thiel M (eds) Evolutionary ecology of social and sexual systems: crustaceans as model organisms. Oxford University Press, Oxford, pp 115-144

Bauer RT (2011) Chemical communication in decapods shrimps: the influence of mating and social systems on the relative importance of olfactory and contact pheromones. In: Breithaupt $\mathrm{T}$, Thiel $\mathrm{M}$ (eds) Chemical communication in crustaceans. Springer, New York, pp 277-296

Bélles X (1998) Endocrine effectors in insect vitellogenesis. In: Coast GM, Webster SG (eds) Recent advances in arthropod endocrinology. Cambridge University Press, Cambridge, pp 71-90

Berry FC, Breithaupt T (2010) To signal or not to signal? Chemical communication by urine-borne signals mirrors sexual conflict in crayfish. BMC Biol 8:1-11

Borowsky B (1991) Patterns of reproduction of some amphipod crustaceans and insights into the nature of their stimuli. In: Bauer RT, Martin JW (eds) Crustacean sexual biology. Columbia University Press, New York, pp 33-49

Brockerhoff A, McLay CL (2005a) Comparative analysis of the mating strategies in grapsid crabs with special reference to two common intertidal crabs Cyclograpsus lavauxi and Helice crassa (Decapoda: Grapsidae) from New Zealand. J Crust Biol 25:507-520

Brockerhoff A, McLay CL (2005b) Mating behaviour, female receptivity and male-male competition in the intertidal crab Hemigrapsus sexdentatus (Brachyura: Grapsidae). Mar Ecol Prog Ser 290:179-191

Bushmann PJ, Atema J (1996) Nephropore rosette glands of the lobster Homarus americanus-possible sources of urine pheromones. J Crust Biol 116:221-231

Bushmann PJ, Atema J (2000) Chemically mediated mate location and evaluation in the lobster, Homarus americanus. J Chem Ecol 26:883-899

Caskey JL, Bauer RT (2005) Behavioral test for a possible contact sex pheromone in the caridean shrimp Palaemonetes pugio. J Crust Biol 25:571-576

Caskey JL, Hasenstein KH, Bauer RT (2009a) Studies on contact sex pheromones of the caridean shrimp Palaemonetes pugio: I. Cuticular hydrocarbons associated with mate recognition. Invertebr Reprod Dev 53:93-103

Caskey JL, Watson GM, Bauer RT (2009b) Studies on contact sex pheromones of the caridean shrimp Palaemonetes pugio: II. The role of glucosamine in mate recognition. Invertebr Reprod Dev $53: 105-116$ 
Chang ES (1995) Physiological and biochemical changes during the molt cycle in decapod crustaceans: an overview. J Exp Mar Biol Ecol 193:1-14

Chang ES (2011) The crustacean endocrine system and pleiotropic chemical messengers. In: Breithaupt T, Thiel M (eds) Chemical communication in crustaceans. Springer, New York, pp 413-430

Chang ES, Kaufman WR (2005) Endocrinology of crustacea and chelicerata. In: Gilbert LI, Latrou K, Gill SS (eds) Comprehensive molecular insect science. Elsevier BV, Oxford, pp 805-842

Chen HY, Dillaman RM, Roer RD, Watson D (2012) Stage-specific changes in calcium concentration in crustacean (Callinectes sapidus) Y-organs during a natural molting cycle, and their relation to the hemolymphatic ecdysteroid titer. Comp Biochem Phys 163:170-173

Christy JH, Rittschof D (2011) Deception in visual and chemical communication in crustaceans. In: Breithaupt T, Thiel M (eds) Chemical communication in crustaceans. Springer, New York, pp 313-333

Cooke IM, Haylett B, Weatherby TM (1977) Electrically elicited neurosecretory and electrical responses of the isolated crab sinus gland in normal and reduced calcium salines. J Exp Biol 70:125-149

Dillaman R, Hequembourg S, Gay M (2005) Early pattern of calcification in the dorsal carapace of the blue crab, Callinectes sapidus. J Morphol 263:356-374

Dillaman R, Roer R, Shafer T, Modla S (2013) The crustacean integument: structure and function. In: Watling L, Thiel M (eds) Functional morphology and diversity. Oxford University Press, New York, pp 140-166

Dunham PJ (1988) Pheromones and behavior in the crustaceans. In: Laufer H, Downer GH (eds) Endocrinology of selected invertebrate types. AR Liss, New York, pp 375-392

Eales AJ (1974). Sex pheromone in the shore crab Carcinus maenas and the site of its release from females. Mar Behav Physiol 2:345-355

Ekerholm M, Hallberg E (2005) Primer and short-range releaser pheromone properties of premolt female urine from the shore crab Carcinus maenas. J Chem Ecol 31:1845-1864

Gleeson RA (1991) Intrinsic factors mediating pheromone communication in the blue crab, Callinectes sapidus. In: Martin JW, Bauer RT (eds) Crustacean sexual biology. Columbia University Press, New York, pp 17-32

Gleeson RA, Adams MA, Smith AB (1984) Characterization of a sex pheromone in the blue crab, Callinectes sapidus crustecdysone studies. J Chem Ecol 10:913-921

Greenaway P (1983) Uptake of calcium at the post-moult stage by the marine crabs Callinectes sapidus and Carcinus maenas. Comp Biochem Physiol 75:181-184

Greenaway P (1985) Calcium balance and moulting in the Crustacea. Biol Rev 60:425-454

Guinot D, Tavares M, Castro P (2013) Significance of the sexual openings and supplementary structures on the phylogeny of brachyuran crabs (Crustacea, Decapoda, Brachyura), with new nomina for higher-ranked podotreme taxa. Zootaxa 3665:1-414

Hardege JD, Terschak JA (2011) Identification of crustacean sex pheromones. In: Breithaupt T, Thiel M (eds) Chemical communication in crustaceans. Springer, New York, pp 373-392

Hardege JD, Jennings A, Hayden D, Muller CT, Pascoe D, Bentley MG, Clare AS (2002) Novel behavioural assay and partial purification of a female-derived sex pheromone in Carcinus maenas. Mar Ecol Prog Ser 244:179-189

Hartnoll RG (1968) Morphology of the genital ducts in female crabs. J Linn Soc Zool 47:279-300

Hartnoll RG (2006) Reproductive investment in Brachyura. Hydrobiologia 557:31-40
Henmi Y, Murai M (1999) Decalcification of vulvar operculum and mating in the ocypodid crab Ilyoplax pusilla. J Zool 247:133-137

Herborg LM, Bentley MG, Clare AS, Last KS (2006) Mating behavior and chemical communication in the invasive Chinese mitten crab Eriocheir sinensis. J Exp Mar Biol Ecol 329:1-10

Horn DHS, Middleton EJ, Wunderlich JA, Hampshire F (1966) Identity of the molting hormones of insects and crustaceans. Chem Commun 1966:339-340

Ituarte RB, Bas C, Luppi TA, Spivak ED (2006) Interpopulational differences in the female reproductive cycle of the southwestern atlantic estuarine crab Chasmagnathus granulatus Dana, 1851 (Brachyura: Grapsoidea: Varunidae). Sci Mar 70:709-718

Kamio M, Derby CD (2011) Approaches to a molecular identification of sex pheromones in blue crabs. In: Breithaupt T, Thiel M (eds) Chemical communication in crustaceans. Springer, New York, pp 393-412

Kamio M, Matsunaga S, Fusetani N (2002) Copulation pheromone in the crab Telmessus cheiragonus (Brachyura: Decapoda). Mar Ecol Prog Ser 234:183-190

Kamio M, Schmidt M, Germann MW, Kubanek J, Derby CD (2014) The smell of moulting: $N$-acetylglucosamino-1,5-lactone is a premoult biomarker and candidate component of the courtship pheromone in the urine of the blue crab, Callinectes sapidus. J Exp Biol 217:1286-1296

Karplus I, Malecha SR, Sagi A (2000) The biology and management of size variation. In: New MB, Valenti WC (eds) Freshwater prawn culture: the farming of Macrobrachium rosenbergii. Blackwell Science, Malden, pp 259-289

Kittredge JS, Terry M, Takahashi FT (1971) Sex pheromone activity of the molting hormone crustecdysone on male crabs (Pachygrapsus crassipes, Cancer antennarius and Cancer anthonyi). Fish Bull 96:337-343

López Greco L, Rodríguez E (1998) Size at the onset of sexual maturity in Chasmagnathus granulatus Dana, 1851 (Grapsidae, Sesarminae): a critical overall view about the usual criteria for its determination. Proc Fourth Int Crust Cong 675-689

McLay CL, Becker C (2015) Reproduction in Brachyura. In: Castro P, Davie PJF, Guinot D, Schram FR, von Vaupel Klein JC (eds) Decapoda Brachyura, treatise on zoology - anatomy, taxonomy, biology. Brill, Leiden, pp 185-243

McLay CL, López Greco L (2011) A hypothesis about the origin of sperm storage in the Eubrachyura, the effects of seminal receptacle structure on mating strategies and the evolution of crab diversity: how did a race to be first become a race to be last? Zool Anzeiger 250:378-406

McLay CL, Sal Moyano MP (2016) Calcium levels in the vulvar opercula of Grapsoids and Ocypodoid crabs (Decapoda: Brachyura). J Crust Biol 36:220-228

Mykles DL (2011) Ecdysteroid metabolism in crustaceans. J Steroid Biochem Mol Biol 127:196-203

Nelson H (1991) Scheduling of reproduction in relation to molting and growth in malacostracan crustaceans. In: Wenner A, Kuris A (eds) Crustacean issues 7. Crustacean egg production. Balkema, Rotterdam, pp 77-113

Reinhart VL, Cromarty SI, Sipala MW, Kass-Simon G (2012) Exposure to the steroid hormone 20-hydroxyecdysone modulates agonistic interactions in male Homarus americanus. Horm Behav 62:605-611

Robertson JD (1960) Ionic regulation in the crab Carcinus maenas (L.) in relation to the moulting cycle. Comp Biochem Physiol $1: 183-212$

Rodríguez EM, Dezi RE (1987) Análisis de la composición del peso vivo en machos de Uca uruguayenis y Chasmagnathus granulata (Crustacea, Decapoda, Brachyura). Physis 45:31-32 
Rodríguez EM, Monserrat JM, Amín OA (1992) Chronic toxicity of ethyl parathion and isobutoxyethanol ester of 2,4-dichlorophenoxyacetic acid to estuarine juvenile and adult crabs. Arch Environ Con Tox 22:140-145

Rodríguez Moreno PA, Medesani DA, Rodríguez EM (2003) Inhibition of molting by cadmium in the crab Chasmagnathus granulata (Decapoda Brachyura). Aquat Toxicol 64:155-164

Roer R, Dillaman R (1984) The structure and calcification of the crustacean cuticle. Am Zool 24:893-909

Roer RD, Halbrook KE, Shafer TH (2001) Glycosidase activity in the post-ecdysial cuticle of the blue crab, Callinectes sapidus. Comp Biochem Physiol B 128:683-690

Sal Moyano MP, Gavio MA, Luppi T (2012a) Mating system of the burrowing crab Neohelice granulata (Brachyura: Varunidae) in two contrasting environments: effect of burrow architecture. Mar Biol 159:1403-1416

Sal Moyano MP, Luppi TA, Gavio MA, Vallina M, McLay CL (2012b) Receptivity of female Neohelice granulata (Brachyura: Varunidae): different strategies to maximize their reproductive success in contrasting habitats. Helgol Mar Res 66:661-674

Sal Moyano MP, Silva P, Luppi T, Gavio MA (2014a) Female mate choice by chemical signals in a semi-terrestrial crab. J Sea Res 85:300-307

Sal Moyano MP, Gavio MA, McLay CL, Luppi T (2014b) Habitatrelated differences in the pre-copulatory guarding and copulation behavior of Neohelice granulata (Brachyura, Grapsoidea, Varunidae). J Sea Res 87:8-16
Shafer TH, Roer RD, Miller CG, Dillaman RM (1994) Postecdysial changes in the protein and glycoprotein composition of the cuticle of the blue crab Callinectes sapidus. J Crust Biol 14:210-219

Skinner DM, Graham DE, Holland CA, Mykles DL, Soumoff C, Yamaoka LH (1985) Control of molting in Crustacea. In: Wenner A (ed) Crustacean issues 3. Factors in adult growth. Balkema, Rotterdam, pp 3-14

Spivak E (2010) The crab Neohelice (=Chasmagnathus) granulata: an emergent animal model from emergent countries. Helgol Mar Res 64:149-154

Subramoniam T (2000) Crustacean ecdysteroids in reproduction and embryogenesis. Comp Biochem Physiol C 125:135-156

Webster SG (2015) Endocrinology of molting. In: Chang ES, Thiel M (eds) The natural history of Crustacea: physiology. Oxford University Press, Oxford, pp 1-35

Wyatt TD (2009) Fifty years of pheromones. Nature 457:262-263

Wyatt TD (2011) Pheromones and behavior. In: Breithaupt T, Thiel $\mathrm{M}$ (eds) Chemical communication in crustaceans. Springer, New York, pp 23-38

Zapata MV, López Greco L, Rodríguez EM (2003) Inducción de crecimiento somático en juveniles del cangrejo Chasmagnathus granulatus (Decapoda, Brachyura). II Congreso Iberoamericano Virtual de Acuicultura (http://www.civa2003.org). 971-977

Zar JH (1999) Biostatistical analysis. Prentice Hall Press, New Jersey

Zhang D, Zhu J, Lin J, Hardege JD (2011) Surface glycoproteins are not the contact pheromones in the Lysmata shrimp. Mar Biol 157:171-176 